\title{
Understanding the Rehabilitation Needs of Korean Patients With Complex Regional Pain Syndrome
}

\author{
In Soo Kim, $\mathrm{MD}^{1}$, Sung Eun Hyun, $\mathrm{MD}^{1}$, Jihong Park, $\mathrm{MD}^{2}$, Jae-Young Lim, MD, $\mathrm{PhD}^{3}$ \\ ${ }^{1}$ Department of Rehabilitation Medicine, Seoul National University Hospital, \\ Seoul National University College of Medicine, Seoul; \\ ${ }^{2}$ Department of Rehabilitation Medicine, Seoul National University Bundang Hospital, Seongnam; \\ ${ }^{3}$ Department of Rehabilitation Medicine, Seoul National University Bundang Hospital, \\ Seoul National University College of Medicine, Seongnam, Korea
}

\begin{abstract}
Objective To evaluate the current status of pain severity and quality of life (QoL) in patients with complex regional pain syndrome (CRPS), and to assess both their perceived needs and any unmet needs of current rehabilitation services.

Methods A single-center questionnaire-based survey was conducted on 47 patients with CRPS who were diagnosed based on Budapest's criteria. It collected demographic and clinical data, and the structured questionnaire included the Brief Pain Inventory (BPI), the Korean version of the World Health Organization Disability Assessment Schedule II (WHODAS-K II), as well as the 5-Level EuroQol-5D (EQ-5D-5L) for measuring the QoL.

Results The average value of BPI and WHODAS-K II were $7.69 \% \pm 2.26 \%$ and $70.49 \% \pm 19.22 \%$, respectively. In the evaluation of their perceived needs and unmet needs for rehabilitation, patients had the highest rehabilitation needs in terms of pain (95.74\%), followed by bodyaches (80.85\%). Regarding their unmet needs, patients had the highest unmet needs in terms of memory impairment (83.33\%), followed by weight management $(72.00 \%)$. According to the regression analysis, only the overall BPI was significantly associated with QoL ( $\mathrm{p}=0.01)$, and a higher BPI value led to poorer results for QoL.

Conclusion In Korea, patients with CRPS do not receive adequate rehabilitation, and they are not satisfied with current received treatments. A more structured and individualized rehabilitation treatment plan is required to manage every aspect related to chronic pain, and provision should be made for improved care guidelines for future CRPS management.
\end{abstract}

Keywords Complex regional pain syndromes, Quality of life, Rehabilitation

Received July 12, 2019; Revised September 4, 2019; Accepted September 11, 2019; Published online May 29, 2020

Corresponding author: Jae-Young Lim

Department of Rehabilitation Medicine, Seoul National University Bundang Hospital, Seoul National University College of Medicine, 82 Gumi-ro 173beon-gil, Bundang-gu, Seongnam 13620, Korea. Tel: +82-31-787-7732, Fax: +82-31-787-4051, E-mail: drlim1@snu.ac.kr

ORCID: In Soo Kim (https://orcid.org/0000-0003-2081-5461); Sung Eun Hyun (https://orcid.org/0000-0003-3114-5504); Jihong Park (https://orcid. org/0000-0001-9401-614X); Jae-Young Lim (https://orcid.org/0000-0002-9454-0344).

(c) This is an open-access article distributed under the terms of the Creative Commons Attribution Non-Commercial License (http://creativecommons.org/ licenses/by-nc/4.0) which permits unrestricted noncommercial use, distribution, and reproduction in any medium, provided the original work is properly cited. Copyright (C) 2020 by Korean Academy of Rehabilitation Medicine 


\section{INTRODUCTION}

Complex regional pain syndrome (CRPS) is a persistent, painful, and disabling condition that usually manifests in response to acute trauma or surgery [1]. It is a multifactorial condition with a complex cause and with a challenging diagnosis as the signs and symptoms vary over time, resulting in severe pain and disability [2]. Incidence rates from 5.46 to 26.2 per 100,000 person-years have been reported, however they were variable and dependent upon the different diagnostic criteria used in the studies $[3,4]$. Two types of CRPS exist: CRPS type I occurs without a nerve lesion and CRPS type II has a detectable nerve lesion. It is even more challenging to diagnose CRPS type I which is not accompanied by any peripheral neuropathy [5]. Likewise, although a debate regarding the diagnosis of CRPS still exists, adiagnosis of CRPS is made based on clinical examination and by using the "Budapest" diagnostic criteria, which were approved by the International Association for the Study of Pain [6].

CRPS has a significant impact on the activity of daily living (ADL) and the quality of life (QoL) of patients due to intractable chronic pain. In particular, chronic CRPS is a challenging and complex bio-psychosocial condition which requires a comprehensive and multidisciplinary approach from direct pain management to physical and psychosocial rehabilitation [7]. Therefore, different types of interventions should be applied together and they could include appropriate medication, invasive therapies, as well as continuous rehabilitation (physical therapy and occupational therapy) [8-14].

A lot of research on the multifactorial origin and maintenance of CRPS are underway and they include studies on new or existing agents that target the different mechanisms of action. Various medications are being explored, including but not limited to steroids, non-steroid antiinflammatory drugs, bisphosphonate, calcitonin, Nmethyl-d-aspartate receptor antagonist, as well as immunomodulation therapy and botulinum toxin A [15] Nevertheless, CRPS is still difficult to treat and it usually evolves into a chronic disease. One of the causes for this progression may be related to the lack of adequate physical and occupational treatment that should be included as a first-line of treatment for CPRS patients [16].

Rehabilitative interventions for CRPS mainly consist of several types of physical and occupational therapy targeted at decreasing pain and edema, increasing range of motion (ROM), promoting normal sensitization, and maximizing limb or body function [12]. Rehabilitative treatments that are aimed at improving limb function and desensitization to pain are a crucial part of CRPS management. However, patients do not receive appropriate or sufficient rehabilitation treatments consistently, despite their needs. Unmet needs are defined as the gap between the needs of patients and the actual receipt of services [17]. Unmet needs for rehabilitative treatments and potential barriers to treatment access should be assessed in patients with CRPS, but their rehabilitation needs have rarely been investigated [18]. A previous qualitative study reported that a lack of access to accurate information was a major unmet need in patients with CRPS [19]. In Korea, rehabilitative treatment is not provided appropriately to patients with CRPS due to a lack of awareness of rehabilitation options available for both patients and healthcare professionals. Although physical and occupational therapy should be considered as the first-line treatment for every CRPS patient, comprehensive rehabilitation therapy is not being applied widely in clinical settings [16]. While rehabilitation for other disabilities is being well developed comparatively, institutional and policy limitations do not allow appropriate rehabilitation services for chronic pain.

Therefore, this study aimed to evaluate the current status of pain severity, pain-related disability and QoL in patients with CRPS in Korea, and to assess both their perceived needs and unmet needs for rehabilitation services.

\section{MATERIALS AND METHODS}

\section{Study population}

A single-center questionnaire-based survey was conducted from September 2017 to February 2019 on patients who were diagnosed with CRPS at the Seoul National University Bundang Hospital. Diagnosis according to the Budapest criteria was based on an objective physical examination in an outpatient clinic and the patient's questionnaire results to evaluate all four distinct categories: sensory, vasomotor, sudomotor/edema, and motor/ trophic $[3,6]$. Patients were recruited from the Department of Rehabilitation Medicine through direct referral from primary care physicians and medical specialists in 
other departments, such as anesthesiologic pain clinics, orthopedic surgery, or neuropsychiatry. Symptoms and signs of the patients were evaluated by a physiatrist or pain specialist according to the Budapest diagnostic criteria. In addition, data were collected only for patients who underwent a three-phase bone scan and electrodiagnosis. After diagnosis, patients who were 18 years or older and able to understand and complete the questionnaires received further information on this study. A total of 47 patients were enrolled after signing informed consents and the study protocol was approved by the Institutional Review Board of Seoul National University Bundang Hospital (No. B-1707-408-303).

\section{Assessment}

Demographic characteristics, CRPS-specific questionnaires, pain, QoL and rehabilitation needs were assessed.

\section{Demographic characteristics}

Collected demographic data included the following: sex, age, marital status (living with/without spouse), religion (with/without religious beliefs), residential area (metropolitan area, city or country), educational status (high school or less/university graduation or higher), employment status (with/without a job), family history, disability judgement, and legal action.

\section{CRPS-specific questionnaires and evaluation}

The CRPS-specific questionnaire included details of the pain and symptoms associated with CRPS: age of onset, the initial event precipitating symptoms, pain location(s), duration of pain, and the worst, least, and average pain severity during the past 24 hours using numeric rating scales.

\section{Pain}

Pain intensity was assessed using the Brief Pain Inventory (BPI), a validated tool using numeric rating scales to measure both the intensity of pain and the interference with patients' life $[4,20]$. Severe, average, and weakest pain within 24 hours and current pain were assessed on a numeric rating scale.

\section{QoL}

General health status related QoL was assessed using the 5-Level EuroQol 5-Dimensional Questionnaire clas- sification (EQ-5D-5L), which comprises five domains: mobility, self-care, usual activities, pain/discomfort, and anxiety/depression [21]. Each dimension is represented by a single item with five levels of responses: no problems, slight problems, moderate problems, severe problems, and extreme problems. The EQ-5D-5L validation study was already conducted in Korea, but the crosswalk index value was not developed yet, so it was calculated using Japanese data [22,23].

\section{Functional evaluation}

We used the Korean version of the 36-item intervieweradministered World Health Organization Disability Assessment Schedule (WHODAS-II) [24] for the evaluation of each individual's function. Each item was linked to a 5 -Likert scale: none $=1$, mild $=2$, moderate $=3$, severe $=4$, and extreme/cannot do $=5$. It also consists of five domains: understanding and communicating, getting around, self-care, getting along with others, and life activities. We summated the scores from every item to obtain each domain score, with a higher score indicating greater disability. Finally, each domain score and the overall WHODAS-II score were converted to a 0-100 scale.

\section{Rehabilitation needs, unmet needs and satisfaction}

Patients' needs and satisfaction levels were measured by a questionnaire related to the unmet needs of cancer survivors $[25,26]$. This part of the questionnaire encompassed three separate categories: (1) the rehabilitation needs of the problems related to CRPS, (2) whether the service was provided or not, and (3) satisfaction with the services if provided. Rehabilitation needs for CRPS related symptoms and discomforts were related to problems such as pain, fatigue, bodyaches, weight management, depression, memory impairment, dependent ADL, and decreased physical performance. Pain refers to pain at the site of CRPS and bodyache is general aching caused by CRPS. In the questionnaire, the unmet needs for rehabilitation services were evaluated by the following questions: "For the last year, have you had any needs regarding this problem?" To the patients who had needs for each item, an additional question "Have you received any rehabilitation services for this problem?" was asked. Those who responded "no" to this question among the patients with perceived needs were defined as the pa- 
tients with unmet needs for rehabilitation services [27]. Unmet needs are expressed as the proportion of the patients with unmet needs to those with perceived needs. Lastly, satisfaction was assessed by asking the question "Have you had your needs fulfilled by the rehabilitation services?" to only those who experienced the rehabilitation service for their CRPS related problems.

\section{Statistical analysis}

The categorical variables are expressed in frequencies and percentages, and the continuous variables were presented as means and standard deviations.

Multiple regression analysis was performed to assess the association between QoL index (EQ-5D-5L) and demographic or clinical data in enrolled patients. To analyze the factors affecting the unmet needs of rehabilitation services, logistic regression analysis was performed with "unmet needs" as the dependent variable. Among many dependent variables (unmet needs), we selected and analyzed two of them (dependent ADL, decreased physical performance) because they correspond to the purpose and goal of rehabilitation therapy. In the case of the independent variable factors, pain (BPI overall, pain average), functional evaluation (WHODAS-II), and educational conditions were considered to be related $[28,29]$. Prior to the two regression analyses, correlation analysis was performed first, and then regression analysis was further analyzed by selecting only relevant variables.

A p-value of less than 0.05 was considered statistically significant. All statistical analyses were conducted using SPSS version 19.0 (IBM SPSS, Armonk, NY, USA).

\section{RESULTS}

\section{Characteristics of CRPS patients}

A total of 47 patients with CRPS were analyzed, and Table 1 shows the distribution of demographic factors, involved limbs, and self-reported symptom severity score of CPRS. The average age was $37.49 \pm 12.42$ years; 27 were female $(57.4 \%)$. Average weight and body mass index (BMI) were $68.24 \pm 14.02 \mathrm{~kg}$ and $24.95 \pm 3.97 \mathrm{~kg} / \mathrm{m}^{2}$, respectively. The average duration from the first onset of symptoms and the questionnaire is $40.72 \pm 46.61$ months. Twenty-six patients (55.3\%) live alone without a spouse; $25(53.2 \%)$ have religious beliefs; about half of the patients had graduated from high school or less education
Table 1. Characteristic factors of the CRPS patients

\begin{tabular}{|c|c|}
\hline Characteristic & Value \\
\hline Age of the questionnaire & $37.49 \pm 12.42$ \\
\hline Age of onset of CRPS (yr) & $34.32 \pm 13.14$ \\
\hline Duration (mo) & $40.72 \pm 46.61$ \\
\hline Weight (kg) & $68.24 \pm 14.02$ \\
\hline $\operatorname{BMI}\left(\mathrm{kg} / \mathrm{m}^{2}\right)$ & $24.95 \pm 3.97$ \\
\hline \multicolumn{2}{|l|}{ Gender } \\
\hline Male & $20(42.6)$ \\
\hline Female & $27(57.4)$ \\
\hline \multicolumn{2}{|l|}{ Marital status } \\
\hline Living with spouse & $21(44.7)$ \\
\hline Living without spouse & $26(55.3)$ \\
\hline \multicolumn{2}{|l|}{ Religion } \\
\hline With religious beliefs & $25(53.2)$ \\
\hline Without religious beliefs & $22(46.8)$ \\
\hline \multicolumn{2}{|l|}{ Residence } \\
\hline Metropolitan area & $23(48.9)$ \\
\hline City or country & $24(51.1)$ \\
\hline \multicolumn{2}{|l|}{ Level of education } \\
\hline High school or less & $27(57.4)$ \\
\hline University or more & $20(42.6)$ \\
\hline \multicolumn{2}{|l|}{ Employment status } \\
\hline With & $12(25.5)$ \\
\hline Without a job & $35(74.5)$ \\
\hline Family history & $1(2.1)$ \\
\hline Disability judgement & $10(21.2)$ \\
\hline Legal action & $9(21.4)$ \\
\hline \multicolumn{2}{|l|}{ Limbs involved } \\
\hline Right upper limb & $7(14.9)$ \\
\hline Left upper limbs & $4(8.5)$ \\
\hline Right lower limb & $14(29.8)$ \\
\hline Left lower limbs & $21(44.7)$ \\
\hline \multicolumn{2}{|c|}{ Severity score of CRPS - self reported } \\
\hline Allodynia & $40(85.1)$ \\
\hline Temperature & $45(95.7)$ \\
\hline Skin color & $37(78.7)$ \\
\hline Sweating & $40(85.1)$ \\
\hline Edema & $39(82.9)$ \\
\hline Trophic changes & $31(66.0)$ \\
\hline Motor changes & $46(97.9)$ \\
\hline Decreased active ROM & $45(95.7)$ \\
\hline
\end{tabular}

Values are presented as mean \pm standard deviation or number (\%).

CRPS, complex regional pain syndrome; BMI, body mass index; ROM, range of motion. 
level (57.4\%); a quarter of the patients had a job (25.5\%). Family history of CRPS was reported by only 1 patient (2.1\%). Ten patients $(21.2 \%)$ had a disability certificate issued by the government and $9(21.4 \%)$ have been engaged in legal battles.The majority of patients reported multiple symptoms of CRPS. The most common symptoms were motor changes (97.9\%), decreased active ROM (95.7\%), and temperature (95.7\%) in decreasing order. Many patients noted other parts of the severity score as well; allodynia (85.1\%), sweating (85.1\%), edema (82.9\%), and skin color $(78.7 \%)$. Only $66.0 \%$ claimed trophic changes.

Table 2. Pain characteristics and quality of life

\begin{tabular}{|c|c|}
\hline & Value \\
\hline \multicolumn{2}{|l|}{ Pain severity } \\
\hline Worst pain & $8.19 \pm 1.91$ \\
\hline Least pain & $4.48 \pm 2.02$ \\
\hline Average pain & $6.24 \pm 1.70$ \\
\hline Pain now & $5.91 \pm 2.15$ \\
\hline Improvement after therapy $(24 \mathrm{hr}, \%)$ & $31.96 \pm 21.46$ \\
\hline \multicolumn{2}{|l|}{ Pain interference (BPI) } \\
\hline Activity & $7.69 \pm 2.26$ \\
\hline Mood & $7.65 \pm 2.57$ \\
\hline Walk & $6.99 \pm 3.23$ \\
\hline Work & $8.15 \pm 2.14$ \\
\hline Relate & $6.72 \pm 3.21$ \\
\hline Sleep & $8.18 \pm 2.85$ \\
\hline Enjoy & $8.26 \pm 2.19$ \\
\hline Overall & $7.66 \pm 2.12$ \\
\hline EQ-5D-5L index & $0.39 \pm 0.16$ \\
\hline \multicolumn{2}{|l|}{ WHODAS-K II dimensions (\%) } \\
\hline Overall & $70.49 \pm 19.22$ \\
\hline Understanding and communicating & $58.30 \pm 20.11$ \\
\hline Getting around & $70.72 \pm 22.72$ \\
\hline Self-care & $60.87 \pm 21.01$ \\
\hline Getting along with people & $62.89 \pm 26.70$ \\
\hline Life activities & $78.45 \pm 17.87$ \\
\hline Participation in society & $78.14 \pm 16.80$ \\
\hline
\end{tabular}

Values are presented as mean \pm standard deviation.

BPI, Brief Pain Inventory; WHODAS-K II, Korean version of the World Health Organization Disability Assessment Schedule II; EQ-5D-5L, 5-Level EuroQol 5-Dimensional Questionnaire.

\section{Pain and QoL}

Table 2 summarizes pain intensity as BPI results. When we asked to evaluate patients' pain during the past 24 hours on the numerical rating scale, patients reported $6.24 \pm 1.70$ as "average pain", $8.19 \pm 1.91$ as "worst pain", and $4.48 \pm 2.02$ as "least pain". The average value of patient-reported pain improvement in a $100 \%$ scale was $31.96 \pm 21.46$ after treatment within 24 hours. According to BPI results, interference with enjoyment was rated the highest as $8.26 \pm 2.19$, followed by work and sleep interference. Mean interference with the relationship with others was the lowest at $6.72 \pm 3.21$. The average EQ-5D-5L index value is $0.39 \pm 0.16$. In the WHODAS-II dimension, life activities domain was rated the highest at $78.45 \pm 17.87$, followed by participation in society domains $(78.14 \pm 16.80)$ and getting around (70.72 \pm 22.72$)$. Understanding and communicating domains were rated the lowest as $58.30 \pm 20.11$.

\section{Rehabilitation needs, unmet needs and satisfaction}

Fig. 1 summarizes the rehabilitation needs, unmet needs, and treatment satisfaction of patients with CRPS. Patients had the highest rehabilitation needs in terms of pain $(95.74 \%)$, followed by bodyaches $(80.85 \%)$, and decreased physical performance (78.72\%). The rehabilitation need for dependent ADL was rated the lowest as $51.06 \%$. Regarding unmet needs, patients had the highest unmet needs in terms of memory impairment (83.33\%), followed by weight management $(72.00 \%)$ and fatigue (59.46\%). However, the lowest of unmet needs was found in the rehabilitation need for the problems related to pain (17.78\%), and the unmet needs of recovery of decreased physical performance, bodyaches, and depressive mood were also rated to be less than $40 \%$. The highest satisfaction was found in the rehabilitation services for fatigue problems $(73.93 \%)$, and the lowest was for weight management (28.57\%).

Factors associated with QoL (EQ-5D-5L) and unmet needs according to the regression analysis

Tables 3 and 4 showed the results of the multiple regression analysis examining factors that affect the EQ-5D$5 \mathrm{~L}$ index and the logistic regression analysis examining correlated variables for unmet needs (dependent ADL and decreased physical performance), respectively. Only the overall BPI was associated with QoL ( $\mathrm{p}=0.01)$, where 


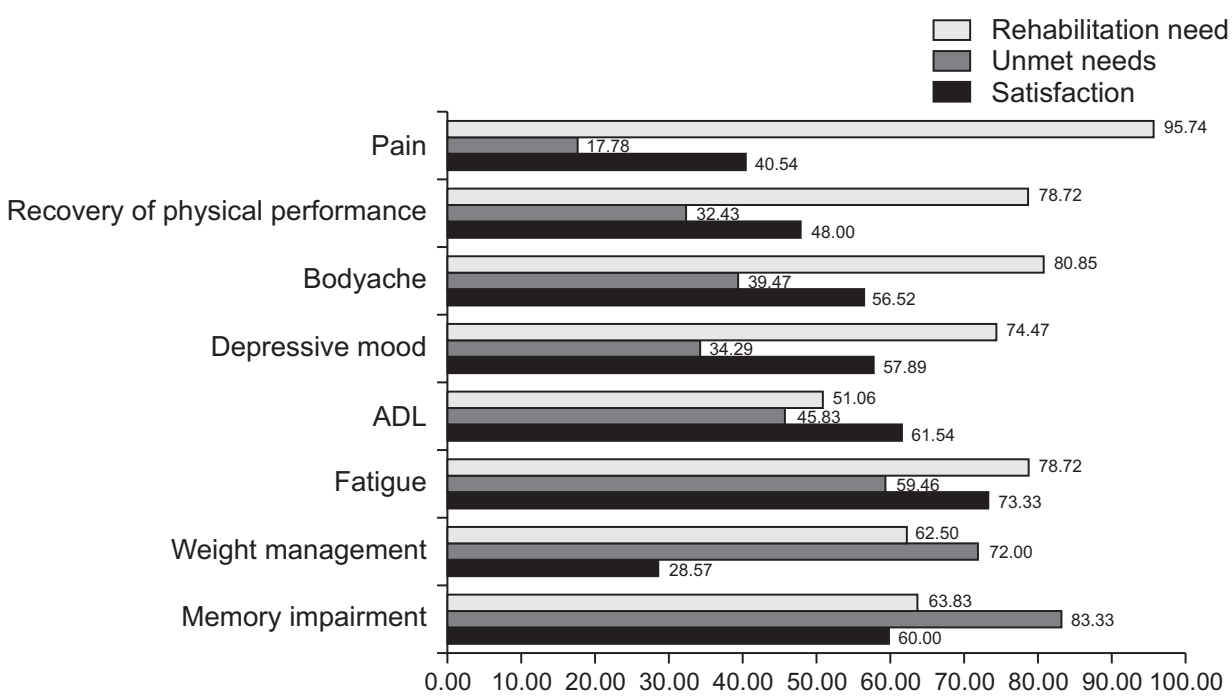

Fig. 1. Rehabilitation needs, unmet needs and satisfaction. Values are presented as percentage (\%). ADL, activities of daily living.

Table 3. Multiple regression analysis for EQ-5D-5L index of CRPS patients

\begin{tabular}{lccc}
\hline & B (coefficient) & $\mathbf{9 5 \%}$ CI & p-value \\
\hline BPI_overall & -0.06 & -0.08 to -0.04 & 0.01 \\
WHODAS-II_overall & 0 & & 0.99 \\
Pain_average & 0 & & 0.75 \\
\hline
\end{tabular}

EQ-5D-5L, 5-Level EuroQol 5-Dimensional Questionnaire; CRPS, complex regional pain syndrome; BPI, Brief Pain Inventory; WHODAS, World Health Organization Disability Assessment Schedule; CI, confidence interval.

Table 4. Logistic regression analysis for unmet needs of CRPS patients

\begin{tabular}{llc}
\hline & \multicolumn{1}{c}{ ADL } & Recovery of physical performance \\
\hline WHODAS-II_overall & $1.05(0.99-1.12)$ & $1.04(0.98-1.10)$ \\
BPI_overall & $1.07(0.59-1.95)$ & $0.94(0.58-1.54)$ \\
Education & $2.54(0.56-11.50)$ & $5.43(1.19-24.77)^{*}$ \\
\hline
\end{tabular}

Values are presented as odds ratio (95\% confidence interval).

CRPS, complex regional pain syndrome; ADL, activities of daily living; WHODAS, World Health Organization Disability Assessment Schedule; BPI, Brief Pain Inventory.

${ }^{*} \mathrm{p}<0.05$.

higher BPI values led to poorer results for QoL (low EQ5D-5L index). Any significant factors associated with the unmet needs of ADL were not found. People with university or higher education reported more unmet needs of recovery of physical performance (odds ratio $=5.43 ; 95 \%$ confidence interval, 1.19-24.77).

\section{DISCUSSION}

This study describes the current status of pain severity, QoL and its relationship with disease symptoms, and both the subjective needs and unmet needs for rehabili- tation services of 47 patients with CRPS. CRPS symptoms were found to interfere significantly with patients' life, daily functioning, and QoL.

The QoL of CRPS patients was shown to deteriorate more when compared with other populations with activity limitations reported in previous studies $[28,30]$. The average EQ-5D-5L index and WHODAS-II values were 0.39 and 70.49 , respectively, in this study; however, the EQ-5D-5L index measured in another study to compare treatment effects in 56 CRPS patients was 0.53 or 0.47 before treatment [31]. In one study evaluating the QoL of Korean polio survivors, the EQ-5D-5L index was 0.68 
[28]. The other study of evaluating QoL in patients with traumatic brain injury (TBI) and spinal cord injury (SCI) in Thailand, WHODAS-II overall score was 66.38 for TBI patients and 52.00 for SCI patients [30]. CRPS patients in our study had the lowest level of QoL when compared to CRPS patients from other countries and other patients with severe disability. As a result, a more comprehensive and improved rehabilitation treatment approach would be necessary to further improve QoL and recovering function of patients living with CRPS. Nonetheless, although rehabilitation treatment is strongly recommended to CRPS patients, current rehabilitation specialists mainly provide only pain management therapy, instead of a coordinated multidimensional program for these patients to learn to cope with their various other symptoms and disabilities [32] (Fig. 1). Various approaches to physical and occupational therapy have been considered as key components in the management of CRPS [2,9]. Usual physical therapy has been shown to help overcome pain and pain-related symptoms such as kinesiophobia, and it improves functional use of the limb. Examples include ROM exercises, contrast baths, functional electrical stimulation, massage, and isometric strengthening exercises to overcome pain. Occupational therapy to increase the use of the affected limb in ADL, along with mirror therapy and applying garments for reducing edema or sensory overload have also been administrated [8]

The unmet needs of rehabilitation treatments in CRPS patients were $48.07 \%$ overall, although there was a difference in each item. Considering that the unmet need for pain is as low as $17.78 \%$, unmet needs for other problems are quite high (32.43\%-83.33\%). Currently, it is difficult to compare directly unmet needs with other studies because there have been no studies reporting the unmet needs of rehabilitation services in CRPS patients as far as we know. However, a study conducted in Denmark reported about $20 \%$ of unmet needs in cancer rehabilitation [33]. The unmet needs for medical services of SCI patients in Korea were reported as $24.8 \%$ [27]. Compared to these studies, our study reported that the unmet needs of CRPS patients in Korea are higher than those of patients with other diseases.

In Korea, even CRPS patients who did receive rehabilitation treatment were found to have low satisfaction of said treatment. Satisfaction with treatment was $53.30 \%$ overall, though variable according to each domain
(28.57\%-73.33\%). Regarding the rehabilitation treatment for pain, which is characterized by relatively low unmet needs, satisfaction was still low (40.54\%). When investigating what treatment was given to CRPS patients, most were pain-related medications or procedures. Patients with CRPS have complex combined physical, psychological, behavioral, and emotional disabilities. CRPS rehabilitation is a process supported by therapists, family members, and carers to achieve patients' maximum potential for each domain [32]. However, CRPS treatments in Korea have focused mainly on managing pain and pain-related symptoms. Some therapists are not aware of "learned disuse" (marked disability developed as a means of avoiding pain) and its management, and they focus only on pain treatments. Our study also reported that the unmet needs in several other domains are quite high. The unmet need for pain is only $17.78 \%$, which is the lowest, but no satisfactory improvement is seen through treatment thereof, resulting in poor satisfaction.

Characteristically, the unmet needs of weight management and memory impairment were high at $72.0 \%$ and 83.3\%, respectively. In contrast, satisfaction showed opposite results; weight management $28.57 \%$, memory impairment $60.00 \%$. There may be several reasons for weight gain, but we surmise that limitations on activity resulted in an increase in body weight. In the domain of memory impairment, excessive use of analgesics is thought to adversely affect cognitive performance [34]. In the case of satisfaction, result interpretation is limited because a very small number of the patients actually received the treatment in respective domain (weight management $=7$; memory impairment $=5$ ). In this study, the absence of objective figures for weight changes and memory impairment also make result interpretation difficult. Future studies should further evaluate weightrelated problems and cognitive performance of CRPS patients using specific evaluation tools.

Regression analysis was performed to clarify factors affecting unmet needs and QoL in CRPS patients. All other factors, including demographic factors, were not correlated. Only the BPI average score influenced QoL (EQ5D-5L). Thus, pain control was found to be important as related to QoL of CRPS patients. Most rehabilitation treatments and efforts aim to control patients' pain, but satisfaction is low as confirmed in this study (40.54\%). The reasons for low satisfaction should be further in- 
vestigated, and we should attempt to find and apply effective treatment methods. For example, graded motor imaginary therapy has been highlighted as a mechanismbased approach for the treatment of CRPS [35]. In a recent systematic review, graded motor imaginary therapy and mirror therapy may provide clinically meaningful improvements in patients with CRPS, although the quality of the supporting evidence is very low [9]. The logistic regression analysis to find the causes of the unmet needs suggests that only "education level" affects the unmet need of "decreased physical performance". Reasons for unmet needs for rehabilitation are multi-dimensional and complex. Many studies indicate that barriers to accessing medical services, educational levels, and household income were essential determinants of unmet needs $[27,28,36]$. Our research also supports that lower educational attainment increases the unmet need of a health care system. Educational level affects those with lower socio-economic status more, and this implies that individuals with lower educational levels have more barriers to overcome to access medical systems $[29,37]$.

\section{Limitation}

The findings of this study need to be carefully interpreted because of the small number of participants. Since CRPS is a rare disease and patients were recruited from a single tertiary care facility, we could not recruit enough patients. In our study, we evaluated the current status of QoL of CRPS patients and the unmet needs of current rehabilitation services. Therefore, there was a lack of evaluation and research on the causes of unmet needs. Accessibility of medical services has been considered to be the main cause of unmet need, and the questionnaire was divided into several questions to identify the cause of unmet need $[36,38]$. Further study on the causes of unmet needs is needed, combining the results of logistic regression and the results of other studies.

In addition, our study was conducted as a cross-sectional survey, and not a longitudinal cohort study. However, other cohort studies such as in the Netherlands, Switzerland, the United States, and the UK concentrated mostly on demographic and clinical phenotypic factors. There has also been a lack of evidence about currently given rehabilitation treatment and the perceived unmet needs of CRPS patients visiting a specialist in the department of rehabilitation $[3,4,39,40]$. On the other hand, we were actively recruiting well-defined CRPS patients and especially pointed out the available rehabilitation treatments at present, with concurrent unmet and satisfying needs, as well as QoL of enrolled patients.

\section{Conclusion}

Current management of CRPS focuses on managing pain and pain-related symptoms using both medical management and rehabilitation therapy. Patients with CRPS do not receive adequate rehabilitation, and they are not satisfied with current received treatments. The unmet needs reported from our study would help to identify a better therapeutic strategy and hopefully would improve treatment outcome in patients with CRPS in the future. The diverse biochemical and clinical characteristics according to the severity and chronicity of the disease should be considered, and a tailored therapeutic strategy to overcome not only the pain and pain-related symptoms but also other unmet needs such as the recovery of physical performance, depressive mood, fatigue, weight management, and memory impairment should be prepared, according to the heterogeneity of the CRPS population.

\section{CONFLICT OF INTEREST}

No potential conflict of interest relevant to this article was reported.

\section{AUTHOR CONTRIBUTION}

Conceptualization: Lim JY, Kim IS, Hyun SE, Park JH. Methodology: Lim JY, Kim IS, Hyun SE. Formal analysis: Lim JY, Kim IS. Project administration: Lim JY, Kim IS. Visualization: Lim JY, Kim IS, Hyun SE, Park JH. Writing - original draft: Lim JY, Kim IS, Hyun SE, Park JH. Writing - review and editing: Lim JY, Kim IS. Approval of final manuscript: all authors.

\section{REFERENCES}

1. Yung Chung O, Bruehl SP. Complex regional pain syndrome. Curr Treat Options Neurol 2003;5:499-511.

2. Galve Villa M, Rittig-Rasmussen B, Moeller Schear Mikkelsen L, Groendahl Poulsen A. Complex regional pain syndrome [published correction appears in 
Musculoskelet Sci Pract. 2019 Oct;43:127]. Man Ther 2016;26:223-30.

3. Sandroni P, Benrud-Larson LM, McClelland RL, Low PA. Complex regional pain syndrome type I: incidence and prevalence in Olmsted county, a populationbased study. Pain 2003;103:199-207.

4. de Mos M, de Bruijn AG, Huygen FJ, Dieleman JP, Stricker BH, Sturkenboom MC. The incidence of complex regional pain syndrome: a population-based study. Pain 2007;129:12-20.

5. Bussa M, Mascaro A, Cuffaro L, Rinaldi S. Adult complex regional pain syndrome type I: a narrative review. PM R 2017;9:707-19.

6. Harden RN, Bruehl S, Stanton-Hicks M, Wilson PR. Proposed new diagnostic criteria for complex regional pain syndrome. Pain Med 2007;8:326-31.

7. Bruehl S. Complex regional pain syndrome. BMJ 2015;351:h2730.

8. Rome L. The place of occupational therapy in rehabilitation strategies of complex regional pain syndrome: comparative study of 60 cases. Hand Surg Rehabil 2016;35:355-62.

9. Smart KM, Wand BM, O'Connell NE. Physiotherapy for pain and disability in adults with complex regional pain syndrome (CRPS) types I and II. Cochrane Database Syst Rev 2016;2:CD010853.

10. Nedeljkovic UD. How to treat complex regional pain syndrome in rehabilitation settings? Acta Chir Iugosl 2013;60:69-75.

11. Lagueux E, Charest J, Lefrancois-Caron E, Mauger ME, Mercier E, Savard K, et al. Modified graded motor imagery for complex regional pain syndrome type 1 of the upper extremity in the acute phase: a patient series. Int J Rehabil Res 2012;35:138-45.

12. D'Arcy Y, Werdell J. Complex regional pain syndrome: treatment and rehabilitation options. Nursing 2008;38 Suppl Therapy:2-3.

13. Moseley GL. Is successful rehabilitation of complex regional pain syndrome due to sustained attention to the affected limb? A randomised clinical trial. Pain 2005;114:54-61.

14. Moseley GL. Graded motor imagery is effective for long-standing complex regional pain syndrome: a randomised controlled trial. Pain 2004;108:192-8.

15. Bussa M, Guttilla D, Lucia M, Mascaro A, Rinaldi S. Complex regional pain syndrome type I: a compre- hensive review. Acta Anaesthesiol Scand 2015;59:68597.

16. Miller C, Williams M, Heine P, Williamson E, O'connell $\mathrm{N}$. Current practice in the rehabilitation of complex regional pain syndrome: a survey of practitioners. Disabil Rehabil 2019;41:847-53.

17. Song Y, Song HJ, Han HR, Park SY, Nam S, Kim MT. Unmet needs for social support and effects on diabetes self-care activities in Korean Americans with type 2 diabetes. Diabetes Educ 2012;38:77-85.

18. Liossi C, Clinch J, Howard R. Need for early recognition and multidisciplinary management of paediatric complex regional pain syndrome. BMJ 2015;351:h4748.

19. Grieve S, Adams J, McCabe C. 'What I Really Needed Was the Truth': exploring the information needs of people with complex regional pain syndrome. Musculoskeletal Care 2016;14:15-25.

20. Yun YH, Mendoza TR, Heo DS, Yoo T, Heo BY, Park HA, et al. Development of a cancer pain assessment tool in Korea: a validation study of a Korean version of the brief pain inventory. Oncology 2004;66:439-44.

21. Brooks R, Rabin R, De Charro F. The measurement and valuation of health status using EQ-5D: a European perspective: evidence from the EuroQol BIOMED Research Programme. Boston, MA: Springer; 2003.

22. Kim SH, Ahn J, Ock M, Shin S, Park J, Luo N, et al. The EQ-5D-5L valuation study in Korea. Qual Life Res 2016;25:1845-52.

23. Shiroiwa T, Ikeda S, Noto S, Igarashi A, Fukuda T, Saito $\mathrm{S}$, et al. Comparison of value set based on DCE and/ or TTO data: scoring for EQ-5D-5L health states in Japan. Value Health 2016;19:648-54.

24. Kim JM, Stewart R, Glozier N, Prince M, Kim SW, Yang SJ, et al. Physical health, depression and cognitive function as correlates of disability in an older Korean population. Int J Geriatr Psychiatry 2005;20:160-7.

25. Shin DW, Park JH, Shim EJ, Hahm MI, Park JH, Park EC. Predictors and outcomes of feeling of insufficient consultation time in cancer care in Korea: results of a nationwide multicenter survey. Support Care Cancer 2012;20:1965-73.

26. Jo JM, Hwang JH, Lee CH, Kang HJ, Yu JN. The need of cancer patients for rehabilitation services. J Korean Acad Rehabil Med 2010;34:691-700.

27. Kim JG, Nam HS, Hwang B, Shin HI. Access to medical 
services in Korean people with spinal cord injury. Ann Rehabil Med 2014;38:174-82.

28. Yang EJ, Lee SY, Kim K, Jung SH, Jang SN, Han SJ, et al. Factors associated with reduced quality of life in polio survivors in Korea. PLoS One 2015;10:e0130448.

29. Hwang J. Understanding reasons for unmet health care needs in Korea: what are health policy implications? BMC Health Serv Res 2018;18:557.

30. Kuo CY, Liou TH, Chang KH, Chi WC, Escorpizo R, Yen CF, et al. Functioning and disability analysis of patients with traumati c brain injury and spinal cord injury by using the world health organization disability assessment schedule 2.0. Int J Environ Res Public Health 2015;12:4116-27.

31. Barnhoorn KJ, van de Meent $\mathrm{H}$, van Dongen RT, Klomp FP, Groenewoud H, Samwel H, et al. Pain exposure physical therapy (PEPT) compared to conventional treatment in complex regional pain syndrome type 1: a randomised controlled trial. BMJ Open 2015;5:e008283.

32. Goebel A, Barker CH, Turner-Stokes L, Atkins RM, Cameron H, Cossins L. Complex regional pain syndrome in adults: UK guidelines for diagnosis, referral and management in primary and secondary care. London: The Royal College of Physicians; 2012.

33. Veloso AG, Sperling C, Holm LV, Nicolaisen A, Rottmann $\mathrm{N}$, Thayssen $\mathrm{S}$, et al. Unmet needs in cancer rehabilitation during the early cancer trajectory: a nationwide patient survey. Acta Oncol 2013;52:372-81.
34. Richards GC, Lluka LJ, Smith MT, Haslam C, Moore B, O'Callaghan J, et al. Effects of long-term opioid analgesics on cognitive performance and plasma cytokine concentrations in patients with chronic low back pain: a cross-sectional pilot study. Pain Rep 2018;3:e669.

35. Gierthmuhlen J, Binder A, Baron R. Mechanismbased treatment in complex regional pain syndromes. Nat Rev Neurol 2014;10:518-28.

36. Allin S, Grignon M, Le Grand J. Subjective unmet need and utilization of health care services in Canada: what are the equity implications? Soc Sci Med 2010;70:46572 .

37. Mollborn S, Stepanikova I, Cook KS. Delayed care and unmet needs among health care system users: when does fiduciary trust in a physician matter? Health Serv Res 2005;40(6 Pt 1):1898-917.

38. Kim JG, Nam HS, Hwang B, Shin HI. Access to medical services in Korean people with spinal cord injury. Ann Rehabil Med 2014;38:174-82.

39. Brunner F, Bachmann LM, Weber U, Kessels AG, Perez RS, Marinus J, et al. Complex regional pain syndrome 1: the Swiss cohort study. BMC Musculoskelet Disord 2008;9:92.

40. Shenker N, Goebel A, Rockett M, Batchelor J, Jones GT, Parker R, et al. Establishing the characteristics for patients with chronic Complex Regional Pain Syndrome: the value of the CRPS-UK Registry. Br J Pain 2015;9:122-8. 